\title{
CLEAR CORNEA SUTURELESS PHACOEMULSIFICATION AND ASTIGMATIC DECAY AFTER TWO YEARS
}

\author{
PIERS PERCIVAL and NICHOLAS BEARE \\ Scarborough
}

\begin{abstract}
SUMMARY
Purpose: To determine whether clear cornea temporal sutureless sections lead to astigmatic decay over a 2 year period.

Method: The difference between (a) pre-operative keratometric cylinder and keratometric cylinder at final follow-up, and (b) spectacle cylinder at 1 month post-operation and final follow-up, was calculated for 43 eyes.

Results: The mean difference in keratometric cylinder between pre-operation and final follow-up was $0.12 \mathrm{D}$ with the rule (WTR) or against the wound. The range was from 0.7 D WTR to 0.4 D against the rule (ATR). Eighty-two per cent of eyes did not change by more than $0.3 \mathrm{D}$. The mean change in spectacle prescription between 1 month post-operation and final follow-up was 0.05 D ATR, range 0.5 D WTR to 1.0 D ATR. At final follow-up $93 \%$ of eyes were seeing $20 / 40$ or better unaided.

Conclusion: A carefully constructed temporal wound can remain astigmatically neutral.
\end{abstract}

We wished to determine whether clinically significant astigmatic decay occurs with sutureless self-sealing temporal corneal wounds. When determining surgically induced astigmatism it is important to consider vector analysis using trigonometric methods ${ }^{1-3}$ when there may be high pre-operative astigmatism, high swings in cylindrical power after surgery and swings in cylindrical axis after surgery. However, these methods are less important when there is little cylindrical alteration to be expected as the result of surgery. We decided to determine the incidence of induced with the rule (WTR) astigmatism in a cohort of 45 consecutive cases of phacoemulsification with foldable implants that had minimal pre-operative

Correspondence to: S. P .B. Percival, FRCOphth, Scarborough Hospital, Scarborough YO12 6QL, UK. Tel: +44 (0)1723 342372. Fax: +44 (0)1723 342427 astigmatism and were followed for between 18 and 33 months, using simple subtraction techniques.

\section{MATERIALS AND METHODS}

Forty-five consecutive eyes of 43 patients were entered into the study and underwent phacoemulsification with foldable lens implants through a temporal sutureless clear cornea wound. Two patients (two eyes) failed to attend the minimum period of 18 months follow-up. Of the remaining 43 eyes, 23 were right eyes and 20 were left eyes. The study commenced in September 1993. Criteria for entry included pre-operative keratometry of less than $1.3 \mathrm{D}$ cylinder, the availability of a foldable lens of the correct power and the absence of intraoperative complications. Patient ages ranged from 41 to 91 years (mean 71.9 years). Twelve patients were male and 29 patients were female.

We defined WTR astigmatism, which is against the temporal wound, as having a cylinder with a plus axis between the $60^{\circ}-90^{\circ}-120^{\circ}$ meridia, and against the rule (ATR) astigmatism as having a plus axis between the $150^{\circ}-180^{\circ}-30^{\circ}$ meridia. The four outcome measures to be determined were:

(i) The difference in keratometric cylinder between pre-operative and final follow-up values using a Topcon OM-4 standard keratometer.

(ii) The number of eyes that developed keratometric WTR astigmatism greater than $0.5 \mathrm{D}$ after surgery.

(iii) The difference in spectacle cylinder required between 1 month and final follow-up following refraction.

(iv) The incidence of an unaided visual acuity of $20 / 30$ and 20/40 at final follow-up.

Wound construction in each case involved a reversecut groove aiming at two-thirds of the corneal thickness and entering the peripheral cornea at the

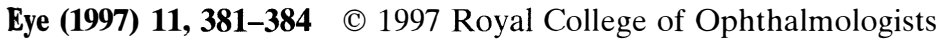




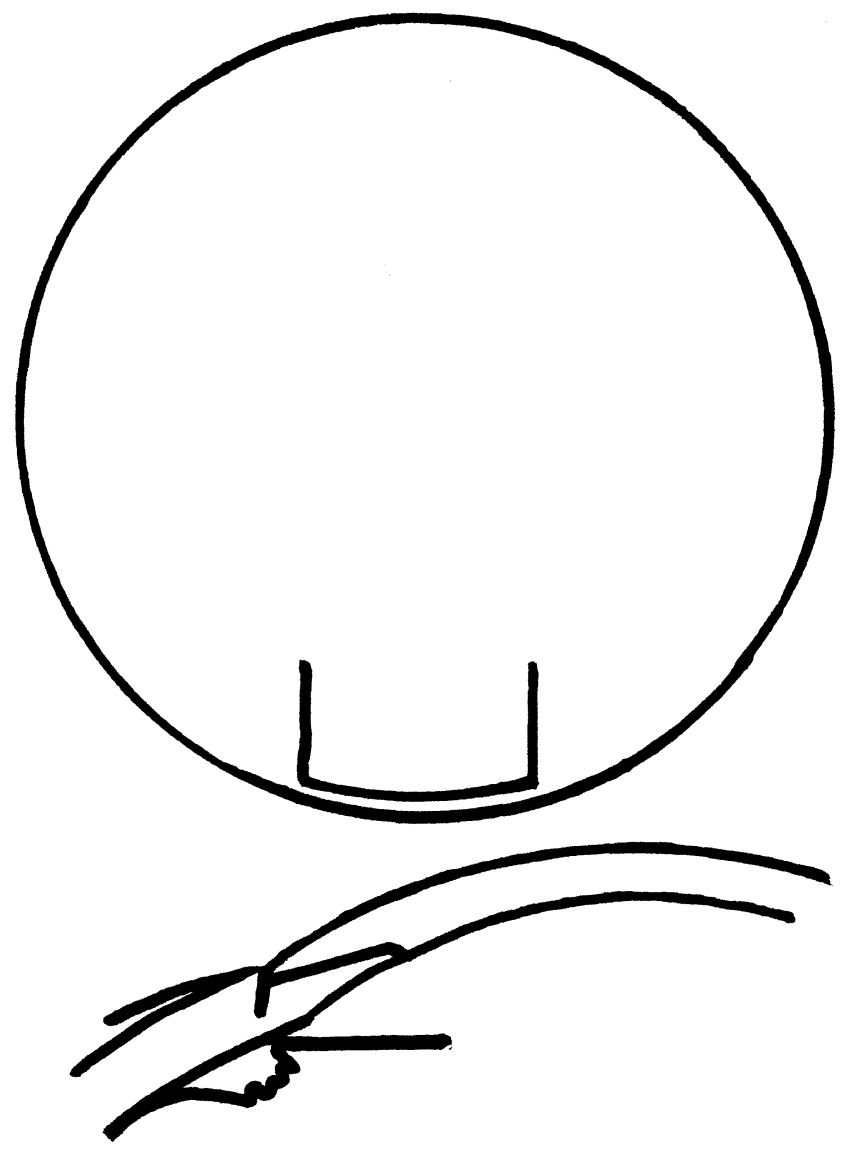

Fig. 1. Wound construction for a clear cornea temporal incision using a $3.2 \mathrm{~mm}$ wide keratome and extending the blade into the corneal stroma for $1.75 \mathrm{~mm}$.

edge of the vascular arcades and angling the incision with a diamond blade towards the limbus. The length of the groove was approximately $3.5 \mathrm{~mm}$. A metal $3.2 \mathrm{~mm}$ keratome was then entered into the groove at approximately half the thickness of the cornea and inclined forwards in the corneal stroma (Fig. 1) for between 1.5 and $2.0 \mathrm{~mm}$. After achieving this distance the tip of the keratome was dipped through Descemet's membrane into the anterior chamber and advanced to its full width. The length of the corneal tunnel was aimed at $1.75 \mathrm{~mm}$. We found that a length greater than $2.1 \mathrm{~mm}$ caused corneal folds during intraocular surgery impairing visibility. Nineteen eyes received an AMO silicone lens style SI $30 \mathrm{NB}$ through an unenlarged incision, 11 eyes received an AMO multifocal silicone lens style SSM 26NB through an incision enlarged to $3.7 \mathrm{~mm}$ and 13 eyes received an Alcon hydrogel lens style 2000SM through an incision enlarged to $3.8 \mathrm{~mm}$. Enlargement was made using a diamond spring caliper which enabled an exact width to be cut in the same plane as the original keratome incision.

\section{RESULTS}

Twenty-five eyes were followed for between 24 and 33 months (mean 28 months). Eighteen eyes were followed for between 18 and 23 months (mean 20 months). Fig. 2 shows the post-operative change in astigmatism by keratometry. One patient ( 1 eye) was too ill to attend for keratometry and the 3 eyes with oblique astigmatism were excluded from this analysis but had insignificant surgically induced WTR astigmatism. Of the remaining 39 eyes, 30 had two keratometric readings recorded at different time intervals on the scattergram and 9 eyes had a single recording. Fig. 3 shows the post-operative change in astigmatism by spectacle refraction. Thirty-six of the 43 eyes had two recordings entered on this scattergram at different time intervals and 7 eyes had a single recording entered. It will be seen from Figs. 2 and 3 that there was no significant difference in outcome measures (i)-(iii) either in terms of

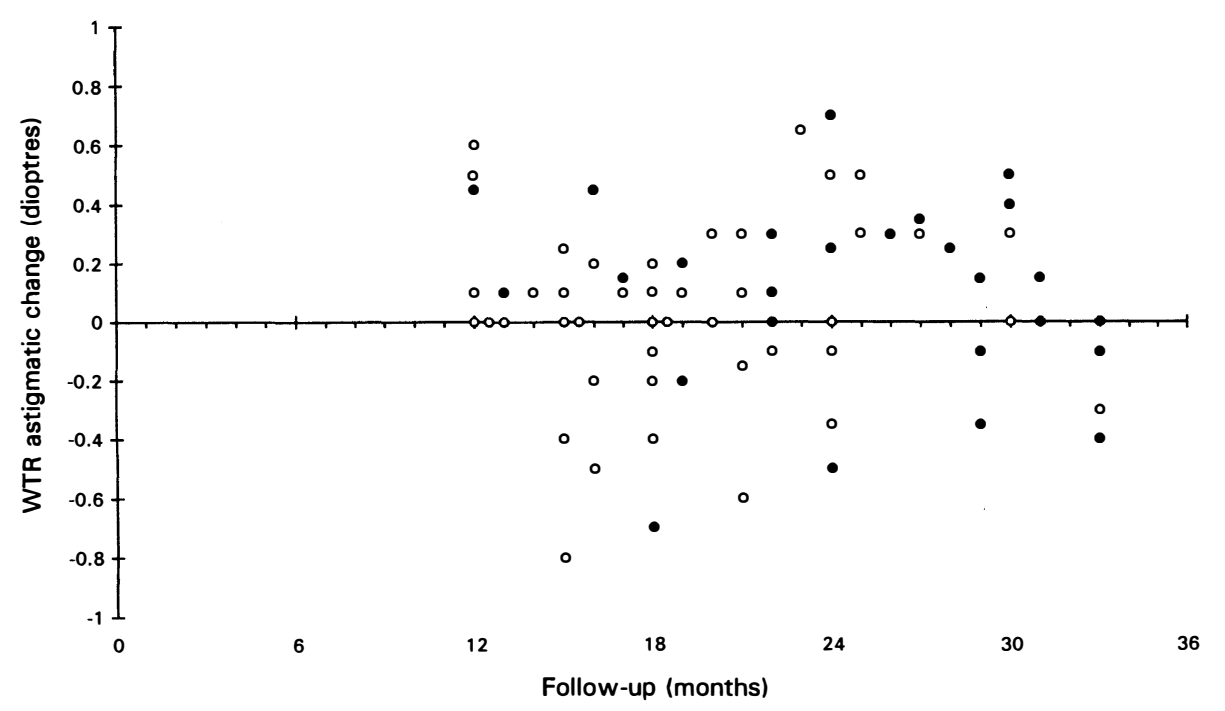

Fig. 2. Scattergram showing post-operative change in astigmatism by keratometry. Filled circles, recordings from eyes with $3.2 \mathrm{~mm}$ wounds; unfilled circles, recordings from eyes with $3.8 \mathrm{~mm}$ wounds. 


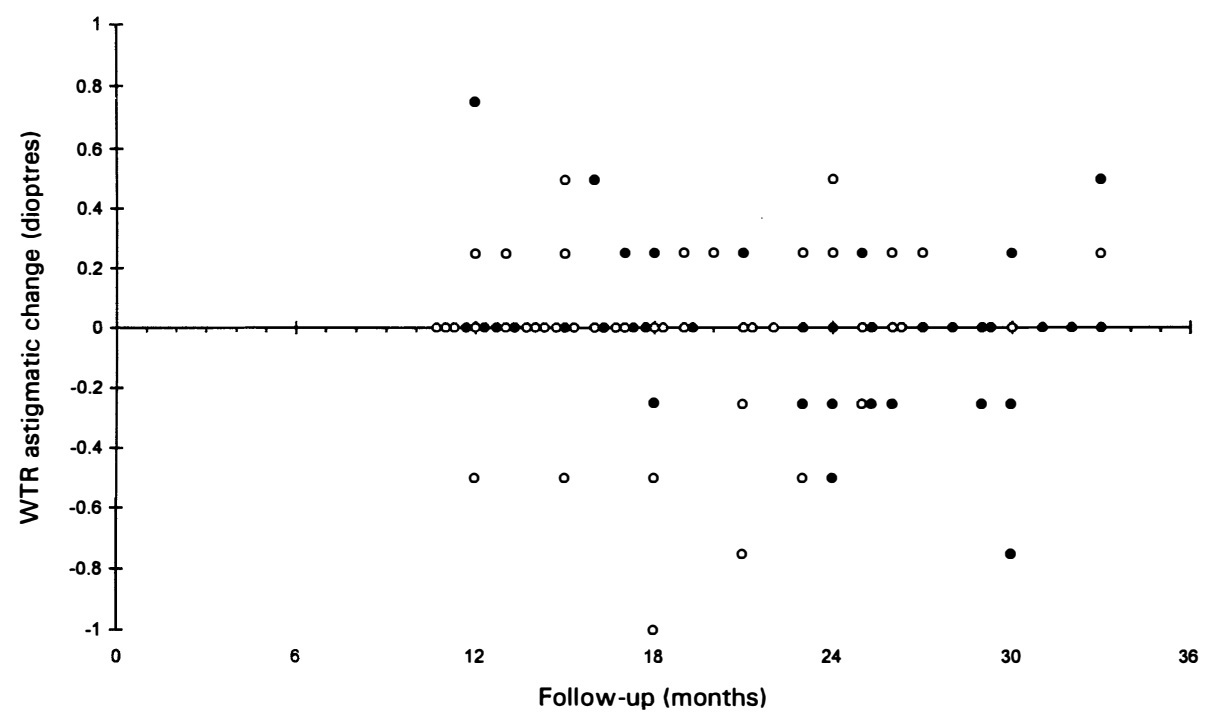

Fig. 3. Scattergram showing post-operative change in astigmatism by spectacle refraction. Filled circles, $3.2 \mathrm{~mm}$ wounds; unfilled circles, $3.8 \mathrm{~mm}$ wounds.

longevity of follow-up or between the groups with enlarged or unenlarged incisions, and therefore final results are taken from the cohort of 43 eyes as a whole. Pre-operative keratometry showed that 24 eyes had astigmatism WTR, 14 eyes had astigmatism ATR, 2 eyes had no astigmatism and 3 eyes had oblique astigmatism between $40^{\circ}$ and $50^{\circ}$. The maximum pre-operative keratometric cylinder was $1.3 \mathrm{D}$ and 34 (79\%) eyes had pre-operative keratometric cylinder of less than 1.0 D.

\section{Surgically Induced Keratometric Astigmatism}

There was no significant change in cylindrical axis. The mean induced WTR astigmatism was $0.12 \mathrm{D}$. The range (Table I) was from $0.7 \mathrm{D}$ WTR to $0.4 \mathrm{D}$ ATR. Three eyes were measured as having developed more than $0.5 \mathrm{D} \mathrm{WTR}$ astigmatism as the result of surgery. Thirty-two eyes $(82 \%)$ did not change by more than 0.3 D WTR, and looking for the $90 \%$ confidence interval it was found that $90 \%$ of eyes changed by $0.1 \pm 0.45 \mathrm{D}$ WTR.

\section{Spectacle Refraction}

No cylindrical axis was found to have altered by more than $10^{\circ}$ between 1 month after surgery and final follow-up. The mean change between 1 month after surgery and final follow-up was $0.05 \mathrm{D}$ ATR.

Table I. Post-operative change in astigmatism

\begin{tabular}{lcc}
\hline Dioptres & $\begin{array}{c}39 \text { eyes } \\
\text { by keratometry }\end{array}$ & $\begin{array}{c}43 \text { eyes } \\
\text { byectacle refraction }\end{array}$ \\
\hline$>0.3$ ATR & 4 & 6 \\
$0.2-0.3$ ATR & 4 & 5 \\
0.15 ATR to 0.15 WTR & 18 & 22 \\
$0.2-0.3$ WTR & 6 & 8 \\
$0.35-0.5$ WTR & 4 & 2 \\
$>0.5$ WTR & 3 & 0 \\
\hline
\end{tabular}

ATR, against the rule; WTR, with the rule.
The range (Table I) was $0.5 \mathrm{D}$ WTR to $1.0 \mathrm{D}$ ATR; 35 of $43(81 \%)$ did not alter by more than $0.25 \mathrm{D}$.

\section{Visual Acuity}

At final follow-up the unaided acuity (Table II) was $20 / 40$ or better in 40 eyes $(93 \%)$ and $20 / 30$ or better in 30 eyes $(70 \%)$. The corrected acuity was $20 / 40$ or better in 42 eyes and $20 / 30$ or better in 41 eyes $(95 \%)$. Two eyes suffered from age-related maculopathy.

\section{DISCUSSION}

Advantages of a clear cornea temporal incision include a faster approach to phacoemulsification with no cautery, less deformation of the globe during surgery, easier intraocular manipulation and visibility, absence of hyphaema even if a patient is anticoagulated, absence of problems from a heavy brow or tight lids, and suitability in the presence of a coexisting filtering bleb. The benefits of self-sealing clear cornea tunnels were first suggested by Fine in 1992. ${ }^{4}$ A further advantage is that the horizontal corneal diameter is wider than the vertical diameter so that a temporal tunnel is at the most distant point from the centre of the cornea. In addition there is less likelihood of astigmatic decay from lid pressure or blinking.

Other authors have shown that most sutureless temporal wounds of between 3.0 and $4.0 \mathrm{~mm}$ are associated with small degrees of WTR induced astigmatism by 6 months to 1 year of follow-up. ${ }^{5-8}$

Table II. Visual acuity at final follow-up (43 eyes)

\begin{tabular}{lcc}
\hline Visual acuity & Unaided & With correction \\
\hline $20 / 20$ or better & 16 & 38 \\
$20 / 30$ & 14 & 3 \\
$20 / 40$ & 10 & 1 \\
$20 / 60$ or worse & 3 & 1 \\
\hline
\end{tabular}


Smaller wounds were associated with less astigmatism than larger wounds. ${ }^{5-7}$ Our results most closely agree with those of Pfleger $\mathrm{et} \mathrm{al}^{7}$ who found a mean of $0.09 \mathrm{D}$ WTR astigmatism for $3.2 \mathrm{~mm}$ incisions and $0.26 \mathrm{D}$ WTR for $4.0 \mathrm{~mm}$ incisions. Our longer followup gives credence to the idea that surgically induced astigmatism can be negligible 2 years after surgery. The implication is that a sutureless temporal wound should not be used to treat even minor degrees of pre-existing ATR astigmatism unless the wound construction is modified.

Steinert and Deacon ${ }^{9}$ demonstrated that manipulation of the phacoemulsification probe and the introduction of a foldable implant through a tight fit can lead to stretching of the wound by up to $0.4 \mathrm{~mm}$. We believe that our unenlarged wounds were also stretched, probably to at least $3.5 \mathrm{~mm}$. However, those wounds enlarged to $3.8 \mathrm{~mm}$ allowed an easy passage of the folded implant and were unlikely to have suffered stretching. We consider, therefore, that with proper wound construction a width of $3.5-3.8 \mathrm{~mm}$ can remain astigmatically neutral.

From Figs. 2 and 3 we could not identify any significant astigmatic shift with the passage of time. Only $8 \%$ of eyes developed WTR keratometric astigmatism greater than $0.5 \mathrm{D}$ over a 2 year period. Some eyes were recorded as having developed astigmatism ATR. We observed no cases of hyphaema, wound dehiscence, iris prolapse or endophthalmitis when using this technique. Clinically the wounds showed a stable refraction and provided the patients with immense satisfaction and excellent unaided acuities. Over a period of up to $2 \frac{3}{4}$ years $82 \%$ of eyes showed either no refractive change or a change of $0.25 \mathrm{D}$. Two changed by $0.5 \mathrm{D}$ WTR. Of the others all were ATR, three changed by $0.5 \mathrm{D}$, two by $0.75 \mathrm{D}$, one by $1.0 \mathrm{D}$. Wound decay was negligible.

This paper was read to the International Ophthalmic Microsurgical Study Group, Tegernsee, September 1996.

Key words: Phacoemulsification, Temporal incision, Astigmatism, Sutureless wound.

\section{REFERENCES}

1. Jaffe NS, Clayman HM. The pathophysiology of corneal astigmatism after cataract extraction. Trans Am Acad Ophthalmol Otolaryngol 1975;79:615-30.

2. Cravy TV. Calculation of the change in corneal astigmatism following cataract extraction. Ophthalmic Surg 1979;10:38-49.

3. Holladay JT, Cravy TV, Kock DD. Calculating surgically induced refractive change following ocular surgery. J Cataract Refract Surg 1992;18:429-43.

4. Fine IH. Self sealing corneal tunnel incision for small incision cataract surgery. Ocular Surg News 1992;1 May:38-9.

5. Kohnen T, Dick B, Jacobi KW. Comparison of induced astigmatism after temporal clear corneal tunnel incisions of different sizes. J Cataract Refract Surg 1995; 21:417-24.

6. Long DA, Monica ML. A prospective evaluation of corneal curvature changes with 3.0 to $3.5 \mathrm{~mm}$ corneal tunnel phacoemulsification. Ophthalmology 1996; 103:226-32

7. Pfleger T, Sokpik C, Menapace R, Scholz U, Weghaust $\mathrm{H}$, Zehetmayer $M$. Long term course of induced astigmatism after clear corneal incision cataract surgery. J Cataract Refract Surg 1996;22:72-7.

8. Kammann JP, Dornbach G. Long term results and indications for clear corneal surgery. Eur J Implant Refract Surg 1995;7:97-100.

9. Steinert RF, Deacon J. Enlargement of incision width during phacoemulsification and folded intraocular lens implant surgery. Ophthalmology 1996;103:220-5. 